\title{
EFEKTIVITAS MODEL NHT BERBANTU LABORATORIUM VIRTUALTERHADAP HASIL BELAJAR DITINJAU DARI KETERAMPILAN PROSES SAINS
}

\section{EFFECTIVENESS OF THE NHT MODEL WITH VIRTUAL LABORATORY TOWARDS LEARNING OUTCOMES IN TERMS OF SCIENCE PROCESS SKILLS}

\author{
Dwi Trisnawati ${ }^{1}$ Yetri $^{2}$ \\ ${ }^{1}$ MTs Miftakhurrohman Mulya Kencana Tulang Bawang Barat \\ ${ }^{2}$ Program Pascasarjana Universitas Islam Negeri Raden Intan Lampung \\ E-mail: dwitrisnawatii@gmail.com
}

Diterima: 30 April 2019. Disetujui: 28 Mei 2019. Dipublikasikan: 31 Juli 2019

\begin{abstract}
This study aims to determine the effectiveness of virtual laboratory-assisted Numbered Head Together (NHT) models in providing good learning outcomes to students who have science process skills. The study was conducted at Bandar Lampung High School 8 with the research method Quasi Experimental Design. Analysis of hypothesis testing data of this study uses two-way variance analysis. Then the effectiveness is known by using the effect size test that is getting the value $d=0.45$, then this result is interpreted using the table of effect size obtained that the laboratory-assisted NHT model affects student learning outcomes by $66 \%$. The conclusion is that virtual laboratory-assisted NHT models provide good learning outcomes, there are differences in physics learning outcomes between high, medium and low science process skills, there is no interaction between learning models with science process skills on learning outcomes and NHT models are effective in improving learning outcomes.
\end{abstract}

Keywords: learning outcomes, numbered head together, science process skill, virtual laboratory.

Abstrak:Penelitian ini bertujuan untuk mengetahui efektivitas model Numbered Head Together (NHT) berbantu laboratorium virtual dalam memberikan hasil belajar yang baik pada peserta didik yang memiliki keterampilan proses sains.Penelitian dilakukan di SMA N 8 Bandar Lampung dengan metode penelitian Quasi Eksperimen Design.Analisis data pengujian hipotesis penelitian ini menggunakan analisis variansi dua jalan. Kemudian keefektifan diketahui dengan menggunakan uji effect size yaitu memperoleh nilai $\mathrm{d}=$ 0,45 , kemudian hasil ini diinterpretasikan dengan menggunakan tabel effect size diperoleh bahwa model NHT berbantu laboratorium ini mempengaruhi hasil belajar peserta didik sebanyak $66 \%$. Memperoleh kesimpulan bahwa model NHT berbantu laboratorium virtual memberikan hasil belajar yang baik, terdapat perbedaan hasil belajar fisika antara keterampilan proses sains tinggi, sedang dan rendah, tidak ada interaksi antara model pembelajaran dengan keterampilan proses sains terhadap hasil belajar dan model NHT efektif dalam meningkatkan hasil belajar.

(C) 2019 Unit Riset dan Publikasi Ilmiah FTK UIN Raden Intan Lampung

Kata kunci: keterampialan proses sains, laboratorium virtual, hasil belajar, numbered head together. 


\section{PENDAHULUAN}

Indonesia baru-baru ini sedang menghadapi revolusi industri keempat diberbagai bidang khususnya pendidikan (Anwar, Saregar, Hasanah, \& Widayanti, 2018). Pendidikan sebagaimana yang tercantum dalam UU. RI. No. 20 tahun 2003 tentang Sistem Pendidikan Nasional pasal 1 ayat 1 menyatakan bahwa:Pendidikan adalah usaha sadar dan terencana untuk mewujudkan suasana belajar dan proses pembelajaran agar peserta didik secara aktif mengembangkan potensi dirinya untuk memiliki kekuatan spiritual keagamaan, pengendalian diri, kepribadian, kecerdasan, akhlak mulia serta keterampilan yang diperlukan dirinya, masyarakat, bangsa, dan Negara(Mohammad Ali, 2009).

Melalui pendidikan diharapkan bangsa ini dapat mengikuti perkembangan dalam bidang sains salah satunya ilmu fisika(Anwar et al., 2018).Fisika merupakan ilmu pengetahuan yang paling mendasar karena berhubungan dengan pengamatan pada alam sekitarnya(Mubarrok \& Mulyaningsih, 2014). Mata pelajaran fisika merupakan pelajaran yang dapat mengembangkan kepribadian(Trianto, 2012) dan kemampuan peserta didik. Pembelajaran fisika dapat menyiapkan peserta didik untuk menghadapi perubahan keadaan di dalam kehidupan yang selalu berkembang.(Sari, 2017).

Perkembangan dalam proses pendidikan tidak terlepas dari peran seorang guru. Guru merupakan seorang pendidik, pembimbing, dan pengembang kurikulum yang dapat menciptakan kondisi dan suasana belajar yang kondusif, membangun suasana belajar menyenangkan, menarik, memberi rasa nyaman, memberikan ruang pada peserta didik untuk berpikir aktif, kreatif, dan inovatif dalam mengeksplorasi dan mengelaborasikemampuannya (Ariyani, Indrawati, \& Mahardika, 2017).Dengan begitu peran guru yaitu mengembangkan pengetahuan dan keterampilan peserta didik. Keterampilan tersebut sering kali diperoleh melalui suatu pengamatan/penemuan.Guru dalam proses pembelajarannya diharapkan mampu menciptakan kondisi belajar yang menantang kreatifitas peserta didik, memotivasi peserta didik agar mencapai tujuan pembelajaran(Trianto, 2012).

Berdasarkan hasil wawancara di SMA N 8 Bandar Lampung peneliti kepada guru bidang studi Fisika yang telah dilakukan, kendala yang sering terjadi saat proses pembelajaran fisika antara lain penggunaan media pembelajaran yang masih jarang ini menyebabkan pelajaran fisika kurang menarik bagi peserta didik,sumber belajar dan sarana laboratorium fisika yang belum memadai, sehingga minat belajar peserta didik juga masih kurang. Kurangnya minat belajar peserta didik ini merupakan salah satu faktor yang menyebabkan hasil belajar peserta didik masih rendah.

Hasil belajar yang menjadi prioritas di sekolah merupakan penilaian ranah kognitif dan afektif, sedangkan ranah psikomotorik masih kurang dikembangkan(Irwandani， 2015). Salah satu penyebab dalam pembelajaran adalah penggunaan model pembelajaran yang kurang tepat. Hal ini menyebabakan pembelajaran didominasi oleh guru, sehingga peserta didik menjadi pasif, mengantuk, berbicara dengan teman, dan bosan dalam proses pembelajaran dikelas khususnya pada materi gerak lurus (Qurniawati, Sugiharto, \& Saputro, 2013). Hal tersebut akan berdampak pada hasil belajar peserta didik (Harahap \& Harahap, 
2012) dan ranah psikomotorik terutama keterampilan proses sains peserta didik.

Kurangnya penilaian keterampilan proses sains peserta didik ini diduga karena belum adanya penggunaan media pembelajaran yang tepat. Pencapaian hasil belajar ditinjau dari keterampilan proses sains diperlukan suatu model pembelajaran dengan menggunakan media pembelajaran yang akanmelibatkan peserta didik aktif menemukan sendiri ideidenya sehingga keterampilannya dapat terus dilatih dan dikembangkan.

Model pembelajaran yang tepat untuk diterapkan dalam pembelajaran salah satunya pembelajaran kooperatif NHT (Numbered Heads Together).(Qurniawati et al., 2013)Pembelajaran kooperatif tipe NHT ini adalah pembelajaran yang dirancang untuk mempengaruhi pola interaksi dan untuk membangun pengetahuanpeserta didik melalui interaksi dengan sumber belajar.(Rahayu, Mardiyana, \& Saputro, 2014).

Guru harusmenciptakan pembelajaran yang menarik dengan model pembelajaran dan menggunakan media untuk menambah minat belajar peserta didik.Implementasi teknologi dalam hal media dibidang pendidikan salah satunya adalah perwujudan pembelajaran dengan memanfaatkan ICT (Information Communication and Technology) untuk menciptakan media, metode dan materi pendidikan yang semakin menarik, interaktif dan komprehensif. Upaya perwujudan pembelajaran modern berupa penggunaan pesonal computer(Sahlin, Tsertsidis, \& Islam, 2017) serta perangkat pendukung lainnya agar dapat meningkatkan keefektifan dalam proses pembelajaran maupun saat pelaksanaan eksperimen.

Salah satu media pembelajaran tersebut adalah aplikasi laboratorium virtual yaitu simulasi Physics Education Technology (PhET). The PhET Team menjelaskan bahwa $P h E T$ adalah situs yang menyediakan simulasi pembelajaran fisika, biologi, kimia, dan matematika (Saregar, 2016). Dengan Phet, peserta didik dapat melakukan percobaan tanpa menggunakan banyak peralatan (Diani, Latifah, Anggraeni, \& Fujiani, 2018).

Dengan menggunakan laboratorium virtual dengan PhET Simulation, laboratorium virtualini mempermudah eksperimen peserta didik tanpamenggunakan alat-alat dalam laboratorium nyata. Penggunaan mediaPhET simuation ini berpengaruh positif terhadap hasil belajar peserta didik (Mubarrok \& Mulyaningsih, 2014).

Model pembelajaran NHT dan laboratorium virtual ini dapat digunakan untuk meningkatkan hasil belajar (Rasyid, Passaribu, \& Kamaludin, 2015). Beda penelitian ini dengan penelitian penelitian sebelumnya yaitu menggunakan menggunakan model pembelajaran NHT namun pada penelitian ini peneliti menggunakan media pembelajaran berupa PhET Simulation untuk meningkatkan hasil belajar dan keterampilan proses sains.

\section{METODE PENELITIAN}

Penelitian ini menggunakan metode penelitian Quasi-eksperimen research. Desain kuasi eksperimen yangdigunakan adalahrandomized control group pretestpascatest design.Populasi dalam penelitian ini adalah seluruh kelas $\mathrm{X}$ semester 1 di SMA N 8Bandar Lampung, Provinsi Lampung Tahun Ajaran 2018/2019 sebanyak 4 kelas. Teknik sampling yang digunakan pada penelitian ini yaituRandom Sampling, karena Random Sampling ini merupakan teknik sampling dengan cara acak dan tidak 
memperhatikan tingkatan yang ada(Sanjaya, 2013).

Instrumen yang digunakan dalam penelitian ini adalah Rencana Pelaksanaan Pembelajaran (RPP) pada pokok bahasanGerak Lurus, Silabus, Tes (Hasil Belajar), lembar observasi (Keterampilan Proses sains), yang sebelunya divalidasi terlebih dahulu kepada tim validasi ahli instrumen perangkat pembelajaran. Untuk tes setelah divalidasi kemudian dianalisis melalui proses uji coba yang kemudian dianalisisuntuk mengetahui validitas, reliabilitas, daya beda, dan tingkat kesukaran soal. Instrumen ini terdiri dari 10 butir soal.

Penelitian ini dilakukan sebanyak empat kali pertemuan. Kegiatan penelitian diawali dengan tes awal (pretest) yang bertujuan untuk mengetahui kemampuan awal peserta didik yang dilakukan selama satu kali pertemuan. Kemudian pada pertemuan kedua selanjutnya menggunakan laboratorium virtualuntuk melakukan praktikum dan diskusi kelompok. Selanjutnya pada pertemuan ketiga tujuan penguasaan materi selanjutnya melakukan kegiatan praktikum meneruskan materi gerak lurus, pada proses praktikum kegiatan penilain lembar observasi dilakukan oleh observer. Kegiatan penelitian diakhiri dengan tes akhir (post-test) yang bertujuan untuk mengetahui efektivitas penggunaan model NHT berbantu laboratorium virtual terhadap hasil belajar ditinjau dari keterampilan proses sains peserta didik.

Analisis data pada penelitian ini menggunakan analisis data statistik dengan melakukan pengujian terhadap nilai pretest dan post-test peserta didik. Uji yang dilaksanakan berupa uji normalitas, homogenitas, dan uji statistik, selanjutnya data yang di dapat untuk menguji hipotesis menggunakan analisis dua varians ANAVA dua jalur dengan menggunakan SPSS.17.Efektivitas penggunaan model NHT berbantu laboratorium virtual terhadap hasil belajar dalam penelitian ini diuji dengan menggunakan uji effect size.

\section{HASIL DAN PEMBAHASAN}

\section{Deskripsi Data Hasil Belajar}

Tes hasil belajar dilaksanakan pada awal dan pertemuan terakhir proses pembelajaran. Data tersebuut disajikan dalam bentuk tabel 1 .

Tabel 1. Hasil belajar

\begin{tabular}{lcc}
\hline \multirow{1}{*}{ Kelas } & \multicolumn{2}{c}{ Rata-Rata Nilai } \\
\cline { 2 - 3 } & Pretest & Posttest \\
Kontrol & 66 & 72 \\
Eksperimen & 68 & 78 \\
\hline
\end{tabular}

Berdasarkan tabel diatas menunjukkan bahwa nilai pretest dan posttest eksperimen lebih rendah dibandingkan kelas kontrol.

Untuk menganalisis kategori tes hasil belajar siswa digunakan skor gain ternormalisasi, $N$-Gain diperoleh dari pengurangan skor posttes dengan skor pretest dibagi oleh skor maksimum dikurang skor pretest. Hasil dari perhitungan $\mathrm{N}$-Gain ini akan digunakan untuk uji effect size.Data disajikan dalam diagram di bawah ini.

Perolehan $N$-Gain hasil belajar peserta didik dari kelas ekperimen dan kelas kontrol dapat dilihat pada Tabel2

Tabel 2. Hasil N-Gain Hasil Belajar

\begin{tabular}{lcc}
\hline Kelas & N-Gain & $\begin{array}{l}\text { Rata-Rata } \\
\text { Nilai }\end{array}$ \\
\hline Kontrol & 0,17 & Rendah \\
Eksperimen & 0,32 & Sedang \\
\hline
\end{tabular}

\section{Deskripsi Data Lembar Observasi Keterampilan Proses Sains}

Observasi ini dilakukan untuk melihat keterampilan proses sains peserta didik selama pembelajaran berlangsung.Data hasil keterampilan proses sains dapat dikategorikan dalam tabel 3 dibawah ini 
Tabel 3. Hasil Kategori KeterampilanProses Sains Kelas Kontroldan Kelas Eksperimen

\begin{tabular}{lccc}
\hline Kelas & Tinggi & Sedang & Rendah \\
\hline Eksperimen & 13 & 9 & 8 \\
Kontrol & 6 & 13 & 11 \\
\hline
\end{tabular}

\section{A. Pengujian Prasyarat Analisis}

Pengujian prasyarat dilakukan dengan tujuan untuk apakah data yang diperoleh terdistibusi normal dan homogen.

\section{Uji Normalitas}

Pengujian yang digunakan untuk mengetahui data terdistribusi normal atau tidak dalam penelitian ini yaitu menggunakan kolmogorov-smirnov menunjukan data terdistribusi normal.Berdasarkan hasil uji normalitas posttest dengan taraf signifikan 0,05 . Jika $\mathrm{L}_{\text {hitung }}<\mathrm{L}_{\text {tabel }}$ maka data berdistribusi normal.

\section{Uji Homogentias}

Uji homogenitas ini dilakukan sebagai prasyarat yang kedua dalam menentukan uji hipotesis yang akan digunakan. Hasil homogenitas posttest kelas kontrol dan kelas eksperimen menggunakan ujihomogeneity of Variance.Demikian dapat disimpulkan bahwa $\mathrm{H}_{0}$ diterima $\mathrm{F}_{\text {hitung }}>\mathrm{F}_{\text {tabel }}$ artinya bahwa populasi tersebut memiliki varians yang sama. Setelah diketahui data berasal dari populasi yang sama. Maka dapat dilanjutkan dengan menggunakan statistik parametrik yaitu ujianalisis varians dua jalan.

\section{Hasil Pengujian Hipotesis}

Pengujian hiposkripsi ini menggunakan uji Analisis varians dua jalan pada aplikasi statistik SPSS 17. Dari tabel 3 terdapat peserta didik yang mempunyai kemampuan berpikir kritis tinggi dan peserta didik yang mempunyai kemampuan berpikir kritis rendah.Dapat disimpulkan bahwa pada kelas eksperimen peserta didik memiliki keterampilan proses sains lebih banyak daripada peserta didik yang memiliki keterampilan proses sains rendah. Sedangkan pada kelas kontrol yang memili keterampilan proses sains lebih banyak daripada peserta didik yang memiliki keterampilan proses tinggi.

Tabel 4. Deskripsi Data Hasil Belajar

\begin{tabular}{|c|c|c|c|c|c|}
\hline Kelas & इData & Maks & Min & $\begin{array}{l}\text { Rata- } \\
\text { rata }\end{array}$ & SD \\
\hline $\begin{array}{l}\text { Ekspe } \\
\text { rimen }\end{array}$ & 26 & 93 & 70 & 82 & 6,7 \\
\hline $\begin{array}{l}\text { Kontr } \\
\text { ol }\end{array}$ & 26 & 88 & 63 & 76 & 8 \\
\hline
\end{tabular}
diperlihatkan hasil belajar menunjukakan bahwa nilai rata-rata hasil belajar kelas eksperimen lebih baik dibandingkan dengan kelas kontrol, dengan sebaran nilai yang jauh berbeda. Hal ini ditunjukkan oleh besarnya nilai standar deviasi (simpangan baku), semakin standar deviasi data mendekati nol, maka sebaran datanya semakin seragam dengan rata-rata nilai data yang ada. Hal ini berarti sebaran data yang diperoleh semakin baik.

Tabel 5. Deskripsi Data Hasil Belajar ditinjau dari

\begin{tabular}{|c|c|c|c|}
\hline Fksner & & Ko & \\
\hline KDS & Fints & $\frac{V D C}{R D}$ & I \\
\hline $\begin{array}{c}\text { KPSt } \\
(\mathrm{x} \geq 85)\end{array}$ & $\frac{\text { ГTек }}{13}$ & $\begin{array}{c}\text { KPSt } \\
(x \geq 79)\end{array}$ & 6 \\
\hline $\begin{array}{c}\text { KPSs } \\
(75<\mathrm{x}<84)\end{array}$ & 9 & $\begin{array}{c}\text { KPSs } \\
(70<\mathrm{x}< \\
78)\end{array}$ & 13 \\
\hline $\begin{array}{c}\mathrm{KPSr} \\
(\mathrm{x} \leq 71)\end{array}$ & 8 & $\begin{array}{c}\text { KPSr } \\
(\mathrm{x} \leq 66)\end{array}$ & 11 \\
\hline
\end{tabular}

Pada tabel 5 dapat dilihat bahwa hasil belajar ditinjau dari kemampuan keterampilan proses sains, Dapat disimpulkan bahwa pada kelas eksperimen peserta didik memiliki keterampilan proses sains lebih banyak daripada peserta didik yang memiliki keterampilan proses sains rendah. Sedangkan pada kelas kontrol yang memili keterampilan proses sains lebih banyak daripada peserta didik yang memiliki keterampilan proses tinggi. 
Tabel 6. Hasil Uji Anova Dua Jalan

\begin{tabular}{cccc}
\hline No & Hipotesis & Sig & $\begin{array}{c}\text { Keputusan } \\
\text { uji }\end{array}$ \\
\hline 1 & Model & $0,001<$ & Diterima \\
& & 0,05 & \\
2 & KPS & $0,009<$ & Diterima \\
& & 0,05 & \\
3 & Interaksi & $0,246>$ & Ditolak \\
& & 0,05 & \\
\hline
\end{tabular}

\section{Hasil Pengujian Efektivitas}

Penelitian ini bermaksud untuk mengetahui efektivitas dari model pembelajaran kooperatif tipe NHT (Numbered Head Together) berbantu laboratorium virtual untuk meningkatkan hasil belajar peserta didik. Efektivitas merupakan pembelajaran untuk mengetahui mengetahui seberapa besar sebuah variabel bebas (model pembelajaran NHT (Numbered Head Together) berbantu laboratorium virtual) dapat berpengaruh terhadap variabel terikat (hasil belajar).

Efektivitas pada penelitian ini diukur menggunakan effect size.Effect size dapat dihitung dengan formulasi yang dijabarkan oleh hake. Efektivitas diukur dengan perbandingan gain kelas eksperimen dan kelas kontrol dengan standar deviasinya.

Hasil uji effect sizepest-test hasil belajar memperoleh nilai $\mathrm{d}=0,45$ kemudian hasil ini diinterpretasikan dengan menggunakan tabel effect size diperoleh bahwa model pembelajaran NHT (Numbered Head Together) berbantu laboratorium virtual ini mempengaruhi hasil belajar peserta didik sebanyak $\quad 66 \%$ sehingga dapat disimpulkan bahwa model pembelajaran NHT (Numbered Head Together) berbantu laboratorium virtual efektif dalam meningkatkan hasil belajar peserta didik.

Hasil uji $N$-Gain menunjukan bahwa rata-rata $N$-Gain kelas eksperimen lebih tinggi dibandingkan kelas kontrol. Hal ini juga dapat menjadi indikator bahwa hasil belajar peserta didik kelas eksperimen yang menggunakan model pembelajaran NHT (Numbered Head Together) berbantu laboratorium virtual meningkat dibandingkan dengan kelas kontrol yang menggunakan DirectInteraction.

Hasil perhitungan pada kelas eksperimen dan kelas kontrol juga diperoleh perbedaan yang signifikan pada $N$-Gain menunjukkan bahwa kelas eksperimen memiliki peningkatan hasil pembelajaran yang lebih besar dibandingkan kelas kontrol.Hal ini juga yang mendasari berhasilnya model pembelajaran NHT (Numbered Head Together) berbantu laboratorium virtual meningkatkan hasil belajar peserta didik.

Berdasarkan uraian diatas, maka dapat disimpulkan bahwa hasil belajar peserta didikakan lebih baik menggunkan model pembelajaran NHT berbantu laboratorium virtualdari pada yang memiliki keterampilan proses sains di atas rata-rata menggunakan pembelajaran direct instruction.

\section{KESIMPULAN}

Berdasarkan hasil analisi data dan pembahasan diatas dapat disimpulkan bahwa model pembelajaran kooperatif tipe NHT (Numbered Head Together) berbantu laboratorium virtual berpengaruh terhadap hasil belajar yang baik pada materi gerak lurus.Ada perbedaan pengaruh pembelajaran kooperatif tipe NHT (Numbered Head Together) berbantu laboratorium virtual dan keterampilan proses sains terhadap hasil belajar peserta didik. Tidak terdapat interaksi antara model pembelajaran dengan keterampilan proses sains tinggi, sedang, rendah terhadap hasil belajar peserta didik. Model pembelajaran 
kooperatif tipe NHT (Numbered Head Together) berbantu laboratorium virtual efektif digunakan dalam proses pembelajaran.

\section{DAFTAR PUSTAKA}

Ali, M. (2009). Pendidikan Untuk Pembangunan Nasional. Bandung: PT. Imperial Bhakti Utama.

Anwar, C., Saregar, A., Hasanah, U., \& Widayanti. (2018). The Effectiveness of Islamic Religious Education in the Universities: The Effects on the Students $\hat{a} €^{\mathrm{TM}}$ Characters in the Era of Industry 4 . 0. Tadris: Jurnal Keguruan Dan Ilmu Tarbiyah, 3(1). https://doi.org/10.24042/tadris.v3i1.2 162

Ariyani, R. D., Indrawati, \& Mahardika, I. K. (2017). Model Pembelajaran Guided Discovery ( GD ) Disertai Media Audiovisual Dalam Pembelajaran IPA (FISIKA) Di SMP. Jurnal FKIP, 6.

Diani, R., Latifah, S., Anggraeni, Y. M., \& Fujiani, D. (2018). Physics Learning Based on Virtual Laboratory to Remediate Misconception in Fluid Material. Tadris: Jurnal Keguruan Dan Ilmu Tarbiyah, 3(2), 167-181. https://doi.org/10.24042/tadris.v3i2.3 321

Harahap, R. H., \& Harahap, M. B. (2012). Efek Model Pembelajaran Advance Organizer Berbasis Peta Terhadap Hasil Belajar Fisika Siswa. Jurnal Penelitian Inovasi Pembelajaran Fisika, 4(2).

Irwandani. (2015). Pengaruh Model Pembelajaran Generatif Terhadap Pemahaman Konsep Fisika Pokok Bahasan Bunyi Peserta Didik MTs Al-Hikmah Bandar Lampung. Jurnal Ilmiah Pendidikan Fisika Al-Biruni,
4(2).

https://doi.org/10.24042/jpifalbiruni. v4i2.90

Mubarrok, M. F., \& Mulyaningsih, S. (2014). Penerapan Pembelajaran Fisika pada Materi Cahaya dengan Media Phet Simulations untuk Meningkatkan Pemahaman Konsep Siswa di SMP. Jurnal Inovasi Pendidikan Fisika (JIPF), 3(1), 77.

Qurniawati, A., Sugiharto, \& Saputro, A. N. C. (2013). Efektivitas Metode Pembelajaran Kooperatif Tipe Numbered Head Together (NHT) Dengan Media Kartu Pintar Dan Kartu Soal Terhadap Prestasi Belajar Siswa Pada Materi Pokok Hidrokarbon Kelas X Semester Genap Sma Negeri 8 Surakarta Tahun Pelajaran 2012/2013. Jurnal Pendidikan Kimia (JPK), 2(3).

Rahayu, S., Mardiyana, \& Saputro, D. R. S. (2014). Ekperimentasi Model Pembelajaran Kooperatif Tipe TAI DAN NHT Pada Pokok Bahasan Relasi Dan Fungsi Ditinjau Dari Adversity Quotient ( AQ ) Siswa Kelas VIII SMP NEGERI Di Kabupaten Pringsewu Propinsi Lampung. Jurnal Elektronik Pembelajaran Matematika, 2(3).

Rasyid, A., Passaribu, M., \& Kamaludin, H. (2015). Pengaruh Model Pembelajaran Kooperatif Tipe Nht (Numbered Heads Together) dan Kemampuan Awal Terhadap Hasil Belajar Siswa Pada Mata Pelajaran Fisika Di SMP Negeri 2 Poso. Jurnal Mitra Sains, 3(1).

Sahlin, J. S., Tsertsidis, A., \& Islam, M. S. (2017). Usages and Impacts of The Integration of Information and Communication Technologies (ICTs) in Elementary Classrooms: Case Study of Swedish Municipality 
Schools. Interactive Learning

Environments, 25(5).

https://doi.org/10.1080/10494820.20

16.1170045

Sanjaya, W. (2013). Penelitian

Pendidikan Jenis, Metode, dan

Prosedur. Jakarta: Kencana.

Saregar, A. (2016). Pembelajaran Pengantar Fisika Kuantum Dengan Memanfaatkan Media phet Simulation Dan LKM Melalui Pendekatan Saintifik: Dampak Pada Minat dan Penguasaan Konsep Mahasiswa. Jurnal Al-BiRuNi, 5(April). https://doi.org/10.24042/jpifalbiruni. v5i1.105

Sari, V. N. (2017). Pengaruh Model Pembelajaran Advance Organizer Terhadap Ketrampilan Berfikir Kritis Dan Sikap Ilmiah Peserta Didik Kelas X Materi Protista SMA Negeri 15 Bandar Lampung. UIN Raden Intan Lampung.

Trianto. (2012). Model Pembelajaran Terpadu. Jakarta: Bumi Aksara. 